\title{
The Inclusion of Economic Endpoints as Outcomes in Clinical Trials Reported to ClinicalTrials.gov
}

\author{
Jordan M. Mitchell, BS, and Julie A. Patterson, PharmD, PhD
}

\begin{abstract}
BACKGROUND: As medication expenditures rise, payers are increasingly demanding evidence of economic value for new medications. The 2015 Professional Society for Health Economics and Outcomes Research (ISPOR) Task Force on Cost-Effectiveness Analysis Alongside Clinical Trials noted that clinical trials are increasingly including health care utilization endpoints to address this rising interest in economic information.

OBJECTIVES: To (a) describe the prevalence of economic endpoints in clinical trials submitted to ClinicalTrials.gov and (b) examine associations between trial characteristics and the inclusion of economic endpoints.

METHODS: This retrospective review of ClinicalTrials.gov data extracted the characteristics of clinical trials that were submitted to ClinicalTrials.gov from January 2004 to December 2018; studied a drug and/or biological; and had a recruitment status of not yet recruiting, recruiting, active but not recruiting, or completed. Studies were classified as containing an economic endpoint based on 2 independent evaluations of the inclusion of endpoints relevant to costs, resource utilization, cost-effectiveness, productivity, absenteeism, presenteeism, or unemployment. Descriptive statistics were used to summarize trial characteristics, and chi-square analyses were used to evaluate differences in characteristics between trials with and without economic endpoints.
\end{abstract}

RESULTS: Of the 104,885 trials included in the study, 1,437 (1.37\%) included an economic endpoint; among later phase (phase $2 / 3,3,4$ ) trials, 939 (2.54\%) included economic endpoints. Compared with studies that did not include economic endpoints, those that did were less often industry funded $(48.0 \%$ vs. $52.0 \%, P<0.001)$ and were for a high-spend specialty condition ( $24.1 \%$ vs. $27.4 \%, P<0.001)$. The proportion of trials that included economic endpoints increased by a small but significant amount over the time period studied, from 1.2\% (2004-2008) to $1.6 \%$ (2014-2018; $P<0.001)$.

CONCLUSIONS: A small but growing number of clinical trials are including economic endpoints. This finding may reflect continued industry concerns surrounding the cost and logistical challenges of piggybacking economic data collection alongside clinical trials and/or manufacturers' preferences for modeling for value demonstration. Future research is needed to better understand barriers to the inclusion of economic endpoints as well as the degree to which incorporating health care resource utilization collected during clinical trials into early economic modeling may reduce payer concerns about model transparency and bias.

J Manag Care Spec Pharm. 2020;26(4):386-93

Copyright $\odot 2020$, Academy of Managed Care Pharmacy. All rights reserved.

\section{What is already known about this subject}

As medication expenditures rise, payers are increasingly demanding evidence of the economic value of new medications during formulary decision making.

To generate early evidence of economic value, pharmaceutical companies and other study sponsors may elect to include economic endpoints in clinical trials.

\section{What this study adds}

This study comprehensively assessed trends in the inclusion of economic endpoints in clinical trials, including trial characteristics associated with the inclusion of economic outcomes.

A small but growing number of clinical trials, most often large, late-stage trials, are including economic endpoints.

Despite the high costs associated with specialty treatments, studies on medications for high-spend specialty conditions were less likely to include economic endpoints.

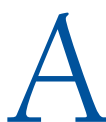
s medication expenditures rise, payers are increasingly looking for evidence of the economic value of new medications during formulary decision making. Payers in one survey ranked health care resource utilization (HCRU) data second behind postmarketing clinical efficacy and safety in terms of usefulness for decision making. In another survey, payers ascribed high strength of evidence to internal financial analyses, external economic reviews, and published cost-effectiveness analyses (CEAs), each of which requires inputs surrounding HCRU. ${ }^{2}$ HCRU data are frequently obtained through retrospective analyses of real-world evidence published years after U.S. Food and Drug Administration (FDA) approval. However, most payers begin forecasting and rate setting as early as 18 months prelaunch and assess new products within 3 months of expected regulatory approval, ${ }^{3-5}$ suggesting an early need for economic evidence.

To meet this demand for early evidence of value, manufacturers often generate economic models using assumptions, expert opinion, or literature to derive the models' HCRU inputs. Nevertheless, many payers report skepticism surrounding pharmacoeconomic evidence generated by pharmaceutical manufacturers, ${ }^{6}$ particularly with regard to economic modeling. ${ }^{7}$ Companies may elect to include economic endpoints in preapproval clinical trials to provide less biased estimates of 
Studies downloaded from ClinicalTrials.gov on January 31, 2019 $\mathrm{N}=297,108$

Excluded studies first submitted before January 1, 2004, and after December 31, 2018 $n=13,013$

Studies first submitted between January 1, 2004, and December 31, 2018 $n=284,095$

Trials with economic endpoints $n=1,437$
Excluded studies pertaining to intervention types other than drugs or biologicals $n=151,002$

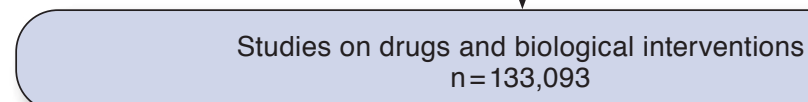

Excluded studies with status other than recruiting, not yet recruiting, active, not recruiting, or completed $n=26,841$

Excluded studies without reported outcomes $n=1,367$

key model parameters or standalone evidence of reductions in HCRU associated with a new therapy.

ISPOR, the Professional Society for Health Economics and Outcomes Research, first published its Good Research Practices for Cost-Effectiveness Analysis Alongside Clinical Trials in 2005 after observing that a growing number of prospective clinical trials were including economic endpoints. ${ }^{8}$ ISPOR updated the Task Force report in 2015, recommending that economic data collection be fully integrated into trials, with HCRU obtained directly from study subjects. The advantages of integrated economic data collection as noted by the Task Force, namely, improved methodological quality of CEAs and enhanced credibility and usefulness to payers, ${ }^{9}$ must be balanced with the associated sample size, data collection, and cost challenges. Little empirical evidence is available surrounding trends in the inclusion of economic endpoints in clinical trials, including the characteristics of trials including these endpoints and changes in the inclusion of economic outcomes over time.

ClinicalTrials.gov is a database of privately and publicly funded clinical studies maintained by the U.S. National Library of Medicine at the National Institutes of Health. ${ }^{10}$ Created as a result of the FDA Modernization Act of 1997 and made public in 2000, ClinicalTrials.gov was established as a registry of clinical trials conducted under investigational new drug applications for experimental drugs used to treat serious or life-threatening conditions; submission requirements were later expanded in the FDA Amendments Act of 2007.10 The ClinicalTrials.gov results database has previously been used to study the characteristics of clinical trials, ${ }^{11,12}$ including sponsorship, ${ }^{13,14}$ design,,${ }^{13,15}$ and outcomes, ${ }^{16}$ with studies often 
focusing on trials in specific disease states such as oncology and cardiovascular disease or specific patient populations..$^{17-23}$

This study aimed to (a) describe the prevalence of economic endpoints in clinical trials submitted to ClinicalTrials.gov and (b) examine associations between trial characteristics and the inclusion of economic endpoints.

\section{Methods}

\section{Data Source and Study Selection}

This retrospective review of ClinicalTrials.gov submissions used data downloaded on January 31, 2019, from the Clinical Trials Transformation Initiative's Aggregate Analysis of ClinicalTrials.gov database, which contains all information about every study registered in ClinicalTrials.gov. ${ }^{24}$ Studies first submitted to ClinicalTrials.gov from January 1, 2004, to December 31, 2018, were eligible for inclusion if they studied a drug and/or biologi$\mathrm{cal}^{14,19}$; had a recruitment status of not yet recruiting; recruiting; active, not recruiting; or completed and reported planned outcomes (Figure 1). ${ }^{19}$

\section{Classification of Study Characteristics}

Studies were classified as containing an economic endpoint if either the name or description of an outcome reported for the study contained the word cost (including cost-effectiveness), resource use or utilization, productivity, absenteeism, presenteeism, or unemployment. Outcomes containing at least 1 of these words pertaining to economic endpoints were independently evaluated by 2 researchers for appropriateness as economic outcomes, with discrepancies resolved by consensus.

The probable funding source was derived from the lead sponsor and collaborator fields using an algorithm previously described by Califf et al. (2012), ${ }^{11}$ with trials being categorized as either industry, National Institutes of Health, U.S. federal, or other. We classified studies as pertaining to a high-cost specialty condition using the Medical Subject Headings (MeSH) and free-text condition terms included in the "conditions" file of the downloaded XML file. ${ }^{25}$ Specifically, the file was used to identify treatments for conditions listed in the top 5 highestcost specialty conditions according to the 2018 Express Scripts drug trend report, as these conditions accounted for more than $90 \%$ of specialty spending included in the report and were the only 5 conditions for which specialty drugs accounted for a majority of condition-specific spending. The 5 conditions included were inflammatory conditions, oncology, multiple sclerosis, human immunodeficiency virus, and hepatitis C virus. ${ }^{26}$ Studies were classified as pertaining to each condition if any of the MeSH or free-text terms in the conditions file related to that condition. ${ }^{25}$
Both U.S.-based and international studies were included given the prominence of health technology assessment around the world. Studies were classified by location into one of the following categories: United States/Canada only ${ }^{27}$; Europe only, where countries were classified as Europe if they were members of the European Union as of May 2019; single country, other, if the single country was neither in the United States, Canada, or Europe; multicountry, including the United States; or multicountry, excluding the United States.

Also included as study design characteristics were study phase $(1,1 / 2,2,2 / 3,3,4$, and not applicable); study design (interventional or observational); number of arms (1, 2, 3, 4, or more); randomization (randomized or nonrandomized); blinding (open, single, double); enrollment size ( $<50,51-100,101-$ $1,000,>1,000$ ); and year of first submission to ClinicalTrials. gov (2004-2008, 2009-2013, 2014-2018). Unless otherwise specified, missing values were noted as "not reported" and excluded from statistical analyses. When an interventional study had not reported allocation, a value of "nonrandomized" was assigned if the number of study arms was listed as " 1 " and the value of blinding was assigned as "open." ${ }^{17}$

\section{Data Analysis}

Descriptive statistics were used to summarize the characteristics of the included trials, including counts and percentages for categorical variables. Chi-square analyses were used to evaluate differences in characteristics between trials with and without economic endpoints. Statistical analyses were conducted using Stata, version 15 (Stata Corp, College Station, TX), with $P<0.05$ denoting statistical significance.

\section{Results}

A total of 297,108 studies were downloaded from ClinicalTrials.gov. After removing studies meeting exclusion criteria (Figure 1), 104,885 remained in the final analysis set. Overall, the included trials were most commonly funded by industry (55.81\%), randomized $(61.69 \%)$, phase 2 (24.39\%), interventional studies (95.82\%) first submitted to ClinicalTrials.gov between 2014 and 2018 (42.22\%; Table 1).

Economic endpoints were included in 1,437 (1.37\%) trials; among later phase (phase 2/3, 3, 4) trials, 939 (2.54\%) included economic endpoints. Approximately $10 \%$ of trials with economic endpoints $(9.46 \%, \mathrm{n}=136)$ reported that the economic outcome was a primary endpoint. Trials with economic endpoints most commonly included measures related to direct or indirect health care costs $(80.86 \%)$, with fewer reporting workplace-related costs $(24.2 \%)$ and planned CEAs (19.49\%). Outcomes related to health care costs were the most common economic outcome among trials with an economic primary endpoint (82.35\%).

Compared with those without economic endpoints, trials reporting economic outcomes systematically differed across nearly all trial characteristics studied (Table 1). While nearly 
The Inclusion of Economic Endpoints as Outcomes in Clinical Trials Reported to ClinicalTrials.gov

\begin{tabular}{|c|c|c|c|c|c|c|c|}
\hline Study phase & \multicolumn{2}{|c|}{$\begin{array}{c}\text { All } \\
\begin{array}{c}(\mathrm{N}=104,885) \\
\mathrm{n}(\%)\end{array}\end{array}$} & \multicolumn{2}{|c|}{$\begin{array}{c}\text { Economic-Related } \\
\text { Endpoints } \\
(\mathrm{n}=1,437) \\
\mathrm{n}(\%)\end{array}$} & \multicolumn{2}{|c|}{$\begin{array}{l}\text { No Economic- } \\
\text { Related Endpoints } \\
(\mathrm{n}=103,448) \\
\mathrm{n}(\%)\end{array}$} & $\begin{array}{l}P \text { Value }^{\mathrm{a}} \\
P<0.001\end{array}$ \\
\hline 1 & 22,932 & (21.9) & 16 & (1.1) & 22,916 & $(22.2)$ & \\
\hline $1 / 2$ & 5,744 & $(5.5)$ & 14 & $(1.0)$ & 5,730 & (5.5) & \\
\hline 2 & 25,582 & $(24.4)$ & 137 & $(9.5)$ & 25,445 & (24.6) & \\
\hline $2 / 3$ & 2,507 & $(2.4)$ & 49 & (3.4) & 2,458 & $(2.4)$ & \\
\hline 3 & 19,076 & $(18.2)$ & 496 & $(34.5)$ & 18,580 & $(18.0)$ & \\
\hline 4 & 15,274 & $(14.6)$ & 394 & $(27.4)$ & 14,880 & (14.4) & \\
\hline N/A & 13,770 & (13.1) & 331 & $(23.0)$ & 13,439 & $(13.0)$ & \\
\hline Study design & & & & & & & $P<0.001$ \\
\hline Interventional & 100,505 & $(95.8)$ & 1,288 & $(89.6)$ & 99,217 & $(95.9)$ & \\
\hline Observational & 4,380 & $(4.2)$ & 149 & $(10.4)$ & 4,231 & $(4.09)$ & \\
\hline Number of arms & & & & & & & $P<0.001$ \\
\hline 1 & 25,070 & $(23.9)$ & 143 & $(10.0)$ & 24,927 & $(24.1)$ & \\
\hline 2 & 43,954 & (41.9) & 785 & $(54.6)$ & 43,169 & $(41.7)$ & \\
\hline 3 & 11,422 & (10.9) & 161 & (11.2) & 11,261 & (10.9) & \\
\hline 4 or more & 24,439 & (23.3) & 348 & $(24.2)$ & 24,091 & (23.3) & \\
\hline Randomization & & & & & & & $P<0.001$ \\
\hline Randomized & 64,701 & $(61.7)$ & 1,095 & $(76.2)$ & 63,606 & $(61.5)$ & \\
\hline Nonrandomized & 34,421 & (32.8) & 192 & (13.4) & 34,229 & (33.1) & \\
\hline Not reported & 5,763 & (5.5) & 150 & $(10.4)$ & 5,613 & (5.4) & \\
\hline Blinding & & & & & & & $P<0.001$ \\
\hline Open & 54,595 & $(52.1)$ & 635 & $(44.2)$ & 53,960 & $(52.2)$ & \\
\hline Single & 5,835 & (5.6) & 107 & $(7.5)$ & 5,728 & $(5.5)$ & \\
\hline Double & 39,464 & (37.6) & 543 & $(37.8)$ & 38,921 & $(37.6)$ & \\
\hline Not reported & 4,991 & $(4.8)$ & 152 & $(10.6)$ & 4,839 & $(4.7)$ & \\
\hline Enrollment size & & & & & & & $P<0.001$ \\
\hline 50 or fewer & 44,287 & $(42.2)$ & 161 & $(11.2)$ & 44,126 & $(42.7)$ & \\
\hline $51-100$ & 20,810 & (19.8) & 160 & $(11.1)$ & 20,650 & $(20.0)$ & \\
\hline $101-1,000$ & 34,820 & $(33.2)$ & 840 & $(58.5)$ & 33,980 & $(32.9)$ & \\
\hline Greater than 1,000 & 4,968 & $(4.7)$ & 276 & $(19.2)$ & 4,692 & $(4.5)$ & \\
\hline Year of enrollment & & & & & & & $P<0.001$ \\
\hline $2004-2008$ & 26,570 & $(25.3)$ & 314 & (21.9) & 26,256 & $(25.4)$ & \\
\hline 2009-2013 & 34,036 & $(32.5)$ & 421 & (29.3) & 33,615 & $(32.5)$ & \\
\hline $2014-2018$ & 44,279 & $(42.2)$ & 702 & $(48.9)$ & 43,577 & $(42.1)$ & \\
\hline Lead sponsor & & & & & & & $P<0.001$ \\
\hline Industry & 58,534 & $(55.8)$ & 690 & $(48.0)$ & 57,844 & $(55.9)$ & \\
\hline $\mathrm{NIH}$ & 8,459 & $(8.1)$ & 62 & $(4.3)$ & 8,397 & $(8.1)$ & \\
\hline U.S. federal & 933 & $(0.9)$ & 14 & $(1.0)$ & 919 & (0.9) & \\
\hline Other & 36,959 & $(35.2)$ & 671 & $(46.7)$ & 36,288 & $(35.1)$ & \\
\hline
\end{tabular}

two thirds of trials with economic endpoints were stage 3 $(34.52 \%)$ or stage $4(27.42 \%)$ trials, only about one third of those without economic endpoints were later stage (stage 3: $17.96 \%$, stage 4: $14.34 \% ; P<0.001)$. Observational designs were also more common among trials with economic outcomes $(10.37 \%$ vs. $4.09 \% ; P<0.001)$, and enrollment size was generally larger in those trials $(P<0.001)$. Economic trials were less often industry funded $(48.02 \%$ vs. $55.95 \% ; P<0.001)$ and conducted exclusively in North America (25.12\% vs. 38.66\%; $P<0.001)$. A statistically significant but numerically small difference was observed in the proportion of trials for medications treating high-cost specialty conditions ( $1.21 \%$ vs. $1.43 \%$; $P=0.005)$, including cancer $(0.80 \%$ vs. $1.53 \% ; P<0.001)$, that included economic endpoints. The proportion of trials with economic endpoints significantly increased over the years studied (2004-2008: 1.2\%; 2014-2018: 1.6\%; $P<0.001$ ). 


\begin{tabular}{|c|c|c|c|c|c|c|c|}
\hline Recruitment status & \multicolumn{2}{|c|}{$\begin{array}{c}\text { All } \\
(\mathrm{N}=104,885) \\
\mathrm{n}(\%)\end{array}$} & \multicolumn{2}{|c|}{$\begin{array}{c}\text { Economic-Related } \\
\text { Endpoints } \\
(\mathrm{n}=1,437) \\
\mathrm{n}(\%)\end{array}$} & \multicolumn{2}{|c|}{$\begin{array}{l}\text { No Economic- } \\
\text { Related Endpoints } \\
(\mathrm{n}=103,448) \\
\mathrm{n}(\%)\end{array}$} & $\frac{P \text { Value }^{\mathrm{a}}}{P<0.001}$ \\
\hline Recruiting & 19,199 & $(18.3)$ & 375 & $(26.1)$ & 18,824 & $(18.2)$ & \\
\hline Not yet recruiting & 4,212 & $(4.0)$ & 90 & $(6.3)$ & 4,122 & $(4.0)$ & \\
\hline Active, not recruiting & 7,442 & $(7.1)$ & 135 & (9.4) & 7,307 & $(7.1)$ & \\
\hline Completed & 74,032 & $(70.6)$ & 837 & $(58.3)$ & 73,195 & $(70.8)$ & \\
\hline Location & & & & & & & $P<0.001$ \\
\hline North America only & 40,356 & $(38.5)$ & 361 & $(25.1)$ & 39,995 & $(38.7)$ & \\
\hline Europe only & 17,436 & $(16.6)$ & 332 & $(23.1)$ & 17,104 & $(16.5)$ & \\
\hline Other single country & 21,302 & $(20.3)$ & 209 & $(14.5)$ & 21,093 & $(20.4)$ & \\
\hline Multicountry - including U.S. & 11,535 & $(11.0)$ & 247 & $(17.2)$ & 11,288 & $(10.9)$ & \\
\hline Multicountry - excluding U.S. & 6,074 & $(5.8)$ & 167 & (11.6) & 5,907 & $(5.7)$ & \\
\hline Not reported & 8,182 & $(7.8)$ & 121 & $(8.4)$ & 8,061 & $(7.8)$ & \\
\hline \multicolumn{8}{|l|}{ Specialty conditions } \\
\hline Any specialty condition & 28,699 & $(27.4)$ & 346 & $(24.1)$ & 28,353 & $(27.4)$ & $P=0.005$ \\
\hline Oncology & 22,720 & $(21.7)$ & 181 & $(12.6)$ & 22,539 & $(21.8)$ & $P<0.001$ \\
\hline Multiple sclerosis & 862 & $(0.8)$ & 18 & (1.3) & 844 & $(0.8)$ & $P=0.069$ \\
\hline Inflammatory condition & 2,485 & $(2.4)$ & 105 & $(7.3)$ & 2,380 & $(2.3)$ & $P<0.001$ \\
\hline HIV & 1,600 & (1.5) & 33 & (2.3) & 1,567 & $(1.5)$ & $P=0.016$ \\
\hline Hepatitis C virus & 1,167 & $(1.1)$ & 11 & $(0.8)$ & 1,156 & $(1.1)$ & $P=0.206$ \\
\hline
\end{tabular}

\section{Discussion}

This study found that despite the growing emphasis on value in pharmaceuticals, few clinical trials for drugs and biologicals include economic endpoints. Over the time period studied (2004-2018), ISPOR twice published task force guidance on including CEA alongside clinical trials, ${ }^{8,9}$ and payers repeatedly emphasized the importance of economic information during formulary decision making. ${ }^{1,2,28}$ While the inclusion of economic outcomes increased over time, the absolute size of the increase (1.2\% of trials in 2004-2008 to $1.6 \%$ in 2014-2018) was limited.

Despite the need for pharmaceutical companies to demonstrate product value to U.S. and international payers, economic endpoints were rare even among industry-sponsored trials. This finding may reflect industry concerns regarding the disadvantages of piggybacking economic data collection alongside clinical trials, logistical challenges, and/or manufacturers' preferences for modeling for value demonstration. Specifically, concerns have been raised surrounding the competing nature of clinical and economic study objectives, limitations in the external validity of HCRU under protocol-driven care, and the use of placebo comparators in clinical trials. ${ }^{13,29}$ Some of these limitations may be addressed as the FDA continues to expand its willingness to incorporate real-world evidence and pragmatic clinical trials into regulatory decision making, though past literature suggests that economic outcomes have rarely been considered in the design and analysis of adaptive clinical trials. ${ }^{30-32}$

Further logistical challenges accompany piggyback evaluation, including sample size, data collection, and cost considerations. First, trials are powered to detect differences in primary clinical outcomes; HCRU often requires larger sample sizes due to high variability, leaving trials unpowered to detect differences in economic outcomes. ${ }^{29}$ Additionally, the respondent, clinician, and cost burdens of collecting HCRU data within the clinical trial or through medical record review present further barriers to including economic endpoints. ${ }^{29}$

Finally, manufacturers may prefer modeling approaches to value generation, though U.S. payers have repeatedly expressed concerns about bias in manufacturer-developed models, particularly surrounding assumptions and a perceived lack of transparency. ${ }^{5-7}$ Economic data from clinical trials may strengthen initial models by providing key model parameters where assumptions, expert opinion, or weaker data may otherwise be used. Furthermore, the use of data collected with validated methods according to a prespecified protocol may address payer concerns regarding transparency. ${ }^{5}$ Future research is needed to better understand the barriers to and facilitators of 
including economic endpoints in industry-funded clinical trials as well as the degree to which incorporating this data into early economic modeling may reduce payer concerns about transparency and bias. Such research would inform the relative advantages of early value demonstration strategies focused on collecting HCRU during trials, economic modeling, or a combination of the two.

Compared with studies that did not include economic endpoints, those that did were more often later stage (i.e., stage 3 or 4 ), larger, and observational. These characteristics may reflect a greater emphasis on using real-world evidence to obtain resource use that is less protocol driven, more generalizable, and more reflective of real-world outcomes. ${ }^{33}$ However, data collected at later stages are less likely to be available during initial formulary decision making when payers are seeking economic information. ${ }^{3-5}$ Interestingly, studies that included economic endpoints were more likely than those that did not to have at least 2 arms, perhaps reflecting the inherently comparative nature of pharmacoeconomic analysis.

This study found that clinical trials for specialty medications for the aggregate of 5 high-cost conditions were no more likely than other trials to include economic endpoints. Given that specialty drugs account for more than half of per-memberper-year spending and are forecasted to continue to increase spending, ${ }^{26}$ demonstration of value is particularly important to payers. ${ }^{34}$ While an overall trend in including economic endpoints in clinical trials for specialty medications was not observed, inflammatory conditions were overrepresented and oncology conditions underrepresented in trials that did include economic endpoints. Notably, cancer medications are often covered under medical, rather than pharmacy, benefits, complicating the utilization management programs that are often informed by pharmacoeconomic analyses. Medicare Part D is also required to cover all drugs in 6 protected classes, including cancer, and few private insurers outright deny coverage for cancer medications. ${ }^{35}$ Finally, economic models for oncology drugs are often driven primarily by the survival gains and cost of a new therapy relative to its existing alternatives, limiting the effect of marginal differences in HCRU captured in clinical trials. These factors together may thereby disincentivize the collection of health economic information during oncology trials.

In contrast to trials for oncology therapies, those for drugs used to treat inflammatory conditions were more likely to include economic endpoints, perhaps reflecting the growing use of cost-containment efforts, including prior authorization, ${ }^{36,37}$ quantity limits, ${ }^{38}$ and formulary exclusion, ${ }^{36}$ in this disease space. Furthermore, value demonstration of products in these therapeutic areas is more likely to include reductions in high-cost hospitalizations and emergency department visits observed in patient populations..$^{39,40}$ Future research is needed to better understand what drug-, disease-, and market-related factors influence the degree to which collecting HCRU data from clinical trials complements a modeling-based value demonstration strategy.

\section{Limitations}

This study has several limitations. First, although ClinicalTrials.gov requires reporting of outcomes during registration, the outcomes that are actually collected and/or published may differ from those initially reported. One study reported that $8 \%$ to $71 \%$ of outcomes reported in publications of trials were not recorded in ClinicalTrials.gov, ${ }^{41}$ suggesting that the number of trials collecting health economic information may be underestimated when using ClinicalTrials.gov as a data source.

Second, ClinicalTrials.gov does not include all trials, since trials not under U.S. jurisdiction are not required to submit to the database. However, as of 2016, approximately two thirds of trials registered in the World Health Organization's International Clinical Trials Registry Platform were registered in ClinicalTrials.gov. ${ }^{12}$

Finally, misclassification bias is possible, particularly in the categorization of studies as containing economic endpoints or not. Most notably, quality of life outcomes, including EuroQol-5D (EQ-5D) and Short Form-36 (SF-36), which are often used to derive utility values for cost-utility analyses, did not qualify a study as containing an economic endpoint unless the description of the measure specifically mentioned its collection for use in an economic analysis. This decision was made given that the majority of quality of life outcomes are not collected specifically for economic analyses and that inclusion of such outcomes in the absence of information about their use would have been likely to falsely inflate the number of studies classified as containing economic endpoints.

\section{Conclusions}

This study found that a small but slowly growing number of clinical trials submitted to ClinicalTrials.gov are including economic endpoints. This finding may reflect continued industry concerns surrounding the cost and logistical challenges of piggybacking economic data collection alongside clinical trials, competing clinical and economic study objectives, and the validity of HCRU data collected during premarketing trials. Manufacturers' preferences for modeling for early value demonstration may also contribute to the paucity of economic endpoints in clinical trials. Future research is needed to better understand barriers to the inclusion of economic endpoints as well as the degree to which incorporating HCRU collected during clinical trials into early economic modeling will reduce payer concerns about model transparency and bias. 


\section{Authors}

JORDAN M. MITCHELL, BS, PharmD candidate, and JULIE A. PATTERSON, PharmD, PhD, Department of Pharmacotherapy $\&$ Outcomes Science, Virginia Commonwealth University School of Pharmacy, Richmond.

AUTHOR CORRESPONDENCE: Julie A. Patterson, PharmD, PhD, Assistant Professor, Department of Pharmacotherapy \& Outcomes Science, Virginia Commonwealth University School of Pharmacy, 410 N. 12th St., Box 980581, Richmond, VA 23298 Tel.: 804.828.0393; E-mail: japatterson2@vcu.edu.

\section{DISCLOSURES}

No outside funding supported this study. Patterson reports past employment by Indivior, unrelated to this study. Mitchell has nothing to disclose.

The research included in this study was presented as a nonreviewed student pharmacist poster at AMCP Nexus 2019; October 30-November 1, 2019; National Harbor, MD.

\section{REFERENCES}

1. Brogan AP, Hogue SL, Mordin MM, Kwong J. United States decision maker perceptions of data from observational studies and other health economics and outcomes research [abstract]. Value Health. 2015;18(3):A75.

2. Choi Y, Navarro RP. Assessment of the level of satisfaction and unmet data needs for specialty drug formulary decisions in the United States. J Manag Care Spec Pharm. 2016;22(4):368-75e. Available at: https://www. jmcp.org/doi/10.18553/jmcp.2016.22.4.368.

3. Fendt P, Ung B, Vogenberg F. The value of pre-FDA approval healthcare economic information exchange between payers and drug manufacturers. Am Health Drug Benefits. 2017;10(8):424-26.

4. Khachatourian KW. Written Statement for the Record Energy \& Commerce Committee, Subcommittee on Health. Examining Medical Product Manufacturer Communications. July 12, 2017. Available at: https:// docs.house.gov/meetings/IF/IF14/20170712/106225/HHRG-115-IF14Wstate-KhachatourianK-20170712.pdf. Accessed February 13, 2020.

5. Fazio L, Rosner A, Drummond M. How do U.S. payers use economic models submitted by life sciences organizations? Value \& Outcomes Spotlight. March/April 2016. Available at: https://www.ispor.org/docs/ default-source/publications/value-outcomes-spotlight/march-april-2016/voseconomic-models.pdf?sfvrsn=d6a38790_2. Accessed February 17, 2020.

6. Mullins CD, Ratner J, Ball DE. How do U.S. health care payers react to and use pharmacoeconomic information? Int J Econ Bus. 2011;18(2):317-30.

7. Hogue SL, Brogan AP, Earnshaw SR, Khan S, Nelsen S. Academy of Managed Care Pharmacy dossiers: use in health care decision making [abstract]. Value Health. 2014;17(3):A18. Available at: https://www.valueinhealthjournal.com/article/S1098-3015(14)00165-X/pdf.

8. Ramsey S, Willke R, Briggs A, et al. Good research practices for costeffectiveness analysis alongside clinical trials: the ISPOR RCT-CEA Task Force report. Value Health. 2005;8(5):521-33.

9. Ramsey SD, Willke RJ, Glick H, et al. Cost-effectiveness analysis alongside clinical trials II-an ISPOR Good Research Practices Task Force report. Value Health. 2015;18(2):161-72.

10. ClinicalTrials.gov. ClinicalTrials.gov background. Available at: https:// clinicaltrials.gov/ct2/about-site/background. Accessed February 13, 2020.

11. Califf RM, Zarin DA, Kramer JM, Sherman RE, Aberle LH, Tasneem A. Characteristics of clinical trials registered in ClinicalTrials.gov, 2007-2010. JAMA. 2012;307(17):1838-47.
12. Zarin DA, Tse T, Williams RJ, Califf RM, Ide NC. The ClinicalTrials.gov results database - update and key issues. N Eng J Med. 2011;364(9):852-60.

13. Roumiantseva D, Carini S, Sim I, Wagner T. Sponsorship and design characteristics of trials registered in ClinicalTrials.gov. Contemp Clin Trials. 2013;34(2):348-55.

14. Keezhupalat SM, Naik A, Gupta S, Srivatsan R, Saberwal G. An analysis of sponsors/collaborators of 69,160 drug trials registered with clinicaltrials.gov. PLoS One. 2016;11(2):e0149416.

15. Bourgeois FT, Murthy S, Mandl KD. Comparative effectiveness research: an empirical study of trials registered in ClinicalTrials.gov. PLoS One. 2012;7(1):e28820

16. Bourgeois FT, Murthy S, Mandl KD. Outcome reporting among drug trials registered in ClinicalTrials.gov. Ann Intern Med. 2010;153(3):158-66

17. Hirsch BR, Califf RM, Cheng SK, et al. Characteristics of oncology clinical trials: insights from a systematic analysis of clinicaltrials.gov. JAMA Intern Med. 2013;173(11):972-79.

18. Subramanian J, Madadi AR, Dandona M, Williams K, Morgensztern D, Govindan R. Review of ongoing clinical trials in non-small cell lung cancer: a status report for 2009 from the ClinicalTrials.gov website. J Thorac Oncol. 2010;5(8):1116-19.

19. Cihoric N, Tsikkinis A, Minniti G, et al. Current status and perspectives of interventional clinical trials for glioblastoma-analysis of ClinicalTrials.gov. Radiat Oncol. 2017;12(1):1-12.

20. Bernardez-Pereira S, Lopes RD, Carrion MJ, et al. Prevalence, characteristics, and predictors of early termination of cardiovascular clinical trials due to low recruitment: insights from the ClinicalTrials.gov registry. Am Heart J. 2014;168:213-19.e1.

21. Alexander KP, Kong DF, Starr AZ, et al. Portfolio of clinical research in adult cardiovascular disease as reflected in ClinicalTrials.gov. J Am Heart Assoc. 2013;2(5):e000009.

22. Pasquali SK, Lam WK, Chiswell K, Kemper AR, Li JS. Status of the pediatric clinical trials enterprise: an analysis of the U.S. ClinicalTrials.gov registry. Pediatrics. 2012;130(5):e1269-e77.

23. Bourgeois FT, Olson KL, Tse T, Ioannidis JPA, Mandl KD. Prevalence and characteristics of interventional trials conducted exclusively in elderly persons: a cross-sectional analysis of registered clinical trials. PLoS One. 2016;11(5):e0155948

24. Clinical Trials Transformation Initiative. Improving public access to Aggregate Content of ClinicalTrials.gov. October 2016. Available at: https:// aact.ctti-clinicaltrials.org/. Accessed February 14, 2020.

25. Tasneem A, Aberle L, Ananth $\mathrm{H}$, et al. The database for aggregate analysis of ClinicalTrials.gov (AACT) and subsequent regrouping by clinical specialty. PLoS One. 2012;7(3):e33677.

26. Express Scripts. Drug trend report. 2018. Available at: https:// my.express-scripts.com/rs/809-VGG-836/images/Express Scripts 2018 Drug Trend Report.pdf. Accessed February 14, 2020.

27. Ross JS, Mulvey GK, Hines EM, Nissen SE, Krumholz HM. Trial publication after registration in ClinicalTrials.gov: a cross-sectional analysis. PLoS Med. 2009;6(9):e1000144.

28. Cournoyer A. Payer survey: new findings on formulary decision-making. Precision All Access Newsletter. February 2018. Available at: https://www. precisionallaccess.com/external-data-and-formulary-decision-makingwhats-the-connection/. Accessed February 14, 2020.

29. O'Sullivan AK, Thompson D, Drummond MF. Collection of healtheconomic data alongside clinical trials: is there a future for piggyback evaluations? Value Health. 2005;8(1):67-79.

30. Sherman RE, Anderson SA, Dal Pan GJ, et al. Real-world evidence-what is it and what can it tell us? N Eng J Med. 2016;375(23):2293-97. Available at: http://buster.zibmt.uni-ulm.de/dpv/dateien/DPV-Wiss-Real-World Evidence What Is It and What Can It Tell Us.pdf. Accessed February 14, 2020. 
31. Gottlieb S. Breaking down barriers between clinical trials and clinical care: incorporating real world evidence into regulatory decision making [speech]. U.S. Food and Drug Administration. January 28, 2019. Available at: https://www.fda.gov/news-events/speeches-fda-officials/breaking-downbarriers-between-clinical-trials-and-clinical-care-incorporating-real-worldevidence. Accessed February 14, 2020.

32. Flight L, Arshad F, Barnsley R, et al. A review of clinical trials with an adaptive design and health economic analysis. Value Health. 2019;22(4):391-98.

33. Katkade VB, Sanders KN, Zou KH. Real world data: an opportunity to supplement existing evidence for the use of long-established medicines in health care decision making. J Multidiscip Healthc. 2018;11:295-304.

34. Sullivan SD. The promise of specialty pharmaceuticals: are they worth the price? J Manag Care Pharm. 2008;14(4):S1-6. Available at: https://www. jmcp.org/doi/10.18553/jmcp.2008.14.S4-A.3.

35. Howard DH, Bach PB, Berndt ER, Conti RM. Pricing in the market for anticancer drugs. J Econ Perspect. 2015;29(1):139-62.
36. Yazdany J, Dudley RA, Chen R, Lin GA, Tseng CW. Coverage for highcost specialty drugs for rheumatoid arthritis in Medicare Part D. Arthritis Rheumatol. 2015;67(6):1474-80.

37. Hartung DM, Johnston KA, Irwin A, Markwardt S, Bourdette DN. Trends In coverage for disease-modifying therapies for multiple sclerosis in Medicare Part D. Health Aff (Millwood). 2019;38(2):303-12.

38. Liang S-Y, Haas JS, Phillips KA. Medicare formulary coverage for topselling biologics. Nat Biotechnol. 2009;27(12):1082-84.

39. Boytsov N, Harrold LR, Mason MA, et al. Increased healthcare resource utilization in higher disease activity levels in initiators of TNF inhibitors among U.S. rheumatoid arthritis patients. Curr Med Res Opin. 2016;32(12):1959-67.

40. Kappelman MD, Porter CQ, Galanko JA, et al. Utilization of healthcare resources by U.S. children and adults with inflammatory bowel disease. Inflamm Bowel Dis. 2011;17(1):62-68.

41. Adam GP, Springs S, Trikalinos T, et al. Does information from ClinicalTrials.gov increase transparency and reduce bias? Results from a five-report case series. Syst Rev. 2018;7(1):59. 